\title{
CASOS RELEVANTES DE LA SUPREMA CORTE DE JUSTICIA DE MÉXICO EN 2018
}

\author{
Leading cases from the Supreme \\ Court of Mexico in 2018
}
ALFONSO HERRERA GARCÍA ${ }^{1}$
Universidad Panamericana
jalfonso.herrera@gmail.com

Cómo citar/Citation

Herrera García, A. (2019).

Casos relevantes de la Suprema Corte de Justicia de México en 2018.

Anuario Iberoamericano de Justicia Constitucional, 23(2), 581-600.

doi: https://doi.org/10.18042/cepc/aijc.23.20

\section{SUMARIO}

I. INTRODUCCIÓN. II. DOBLE JORNADA DE LAS MUJERES TRABAJADORAS. III. SEGURIDAD SOCIAL DE LAS TRABAJADORAS DEL HOGAR. IV. IDENTIDAD DE GÉNERO AUTOPERCIBIDA (REASIGNACIÓN SEXO-GENÉRICA). V. REPRODUCCIÓN ASISTIDA DE LAS PAREJAS DEL MISMO SEXO Y FILIACIÓN DE SUS HIJOS. VI. EDUCACIÓN INCLUSIVA DE LOS NIÑOS Y NIÑAS CON DISCAPACIDAD. VII. VIDA Y SALUD DE LOS NIÑOS FRENTE A CREENCIAS RELIGIOSAS DE SUS PADRES. VIII. PROTECCIÓN DEL BIENESTAR ANIMAL FRENTE A EXPRESIONES CULTURALES: LA PROHIBICIÓN DE PELEAS DE GALLOS. IX. PRECISIÓN AL FUERO JURISDICCIONAL DEL ORDEN MILITAR. X. MODALIDADES LEGALES DEL DERECHO DE RÉPLICA. XI. INSPECCIONES POLICIALES Y GEOLOCALIZACIÓN EN EL CÓDIGO NACIONAL DE PROCEDIMIENTOS PENALES. XII. CONSTITUCIÓN DE LA CIUDAD DE MÉXICO: ¿̇FEDERALISMO DE LOS DERECHOS HUMANOS? XIII. INCONSTITUCIONALIDAD DE LA LEY DE SEGURIDAD INTERIOR. XIV. CONSIDERACIÓN CONCLUSIVA. BIBLIOGRAFíA.

1 Profesor de posgrado en la Facultad de Derecho de la Universidad Panamericana (campus Ciudad de México). 


\section{INTRODUCCIÓN}

En esta crónica se hace referencia a los casos más relevantes ante la Suprema Corte de Justicia de la Nación en México a lo largo de 2018. La selección de los casos toma en consideración su impacto sobresaliente en el ordenamiento jurídico del país o en la opinión pública ${ }^{2}$. Para cumplir con el propósito de esta reseña, que es centralmente informativo, se reducen a la mínima expresión consideraciones críticas sobre los criterios considerados.

No es casualidad que la práctica totalidad de los casos aquí reseñados se relacione con la interpretación de derechos fundamentales. Esto es así porque ese ha sido el sector de la justicia constitucional que ha significado una genuina impronta en la jurisprudencia durante este año, tal como lo fue en los inmediatos anteriores. Este no era un escenario visible hace poco tiempo (hace una década, al menos) en el trabajo cotidiano de la Suprema Corte mexicana.

\section{DOBLE JORNADA DE LAS MUJERES TRABAJADORAS}

Una mujer casada bajo el régimen de separación de bienes solicitó de su exesposo una compensación por el $50 \%$ de los bienes que adquirieron durante el matrimonio. Durante los cuarenta años de vínculo matrimonial, ella se dedicó preponderantemente al cuidado del hogar y de sus tres hijas. Aunque incursionó en alguna actividad profesional, su situación le impidió desarrollarse laboralmente en igualdad de circunstancias que su exmarido.

En las primeras instancias judiciales su pretensión fue negada porque se consideró que el derecho a esa compensación exigía la demostración de que nunca había tenido absolutamente ninguna actividad profesional. Se le exigió demostrar que se había dedicado de manera exclusiva al cuidado del hogar.

En el amparo directo en revisión 4883/2017, la 1. a Sala consideró que cuando las mujeres se han dedicado más tiempo que sus parejas al trabajo doméstico y no recibieron remuneración alguna con motivo de ello es razonable pensar que no pudieron desarrollarse profesionalmente en igualdad de condiciones que sus exparejas. También puede concluirse que esa ha sido una razón por la que no pudieron haber adquirido la misma cantidad de bienes.

La negativa de la compensación solicitada no protege adecuadamente a los cónyuges que asumieron las cargas domésticas y familiares sin recibir a cambio una remuneración económica. Esta situación invisibiliza el trabajo

2 En esa tarea, fue inevitable tomar en cuenta la selección que conjuntamente realizamos en el trabajo Herrera García, Niembro Ortega y Spigno (2019). 
doméstico y las dificultades de padecer lo que debe calificarse como doble jornada laboral. Además, surte un impacto desproporcionado en las mujeres, que son quienes, desde la perspectiva estadística, se dedican en mayor medida a estas tareas.

Se tiene derecho a la compensación cuando el cónyuge que la solicite demuestre que se dedicó a las tareas domésticas y que ello le trajo por consecuencia un costo de oportunidades laborales. Ese derecho subsiste aun cuando se compruebe que pudo dedicar algún tiempo a un trabajo remunerado, o aunque se acredite que ha recibido ayuda de otras personas en las labores del hogar (como empleados domésticos). Estas situaciones no necesariamente subsanan el costo de asumir con preponderancia esas cargas ${ }^{3}$.

Posteriormente, en el amparo directo en revisión 7470/2017, la propia 1. a Sala reiteró ese criterio, haciéndolo extensivo a las parejas unidas en concubinato. En este caso, se hizo incluso énfasis en que el derecho a la igualdad y a la no discriminación debe regir en la compensación. Su finalidad es remediar la asimetría al momento de disolverse el matrimonio o el concubinato.

En este juicio, incluso se había comprobado que la mujer solicitante de la compensación tenía el carácter de socia y accionista de diversas personas morales. La Corte consideró que ello no debía hacer presumir que invirtió tiempo que le impidiera dedicarse a las labores cotidianas del hogar y al cuidado de los hijos. La cotidianidad no debe interpretarse en el sentido de prioridad o prevalencia del trabajo del hogar sobre otras actividades a efectos de una compensación. Debe interpretarse en el sentido de que esas cargas se asumen de forma habitual o frecuente, en mayor medida, que la pareja. El propósito de este razonamiento es también evitar aproximaciones estereotípicas; contrarias, por tanto, al derecho a la igualdad de géneró ${ }^{4}$.

\section{SEGURIDAD SOCIAL DE LAS TRABAJADORAS DEL HOGAR}

El trabajo doméstico también fue motivo de análisis desde la perspectiva del derecho a la seguridad social y a la no discriminación de personas que se

3 Ponente: Arturo Zaldívar Lelo de Larrea. Unanimidad de cuatro votos. Sesión del 28 de febrero de 2018. De este amparo se derivaron las tesis aisladas: 1a. CCXXVIII/2018, 1a. CCXXIX/2018 y 1a. CCXXX/2018, publicadas en el Semanario Judicial de la Federación (en adelante, SJF) el 7 de diciembre de 2018.

4 Ponente: José Ramón Cossío Díaz. Unanimidad de cinco votos. Sesión del 4 de julio de 2018. A partir de este caso, se publicaron las tesis aisladas: 1a. CCXXVI/2018 y 1a. CCXXVII/2018, SJF, de 7 de diciembre de 2018. 
dedican cotidianamente a esa labor. La Ley Federal del Trabajo y la Ley del Instituto Mexicano del Seguro Social excluyen el trabajo doméstico del régimen obligatorio de la seguridad social. En México, el trabajo doméstico ha padecido condiciones inadecuadas, jornadas extensas e indeterminadas, así como bajos salarios. Estas condiciones se encuentran alejadas de un concepto razonable de trabajo digno. La señalada exclusión legal se advirtió como un factor centralmente relevante de una discriminación.

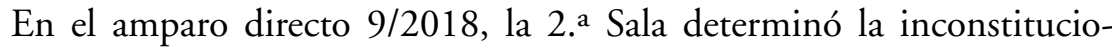
nalidad de la omisión legal de una obligación de los patrones: inscribir a las empleadas domésticas demandantes en el régimen obligatorio de seguridad social. No se advirtió una razón constitucionalmente válida para que la legislación excluya el trabajo doméstico del referido régimen obligatorio. La falta de acceso real a prestaciones sociales puede afectar a los medios de subsistencia e ingresos de estas trabajadoras y para construir un proyecto de vida en condiciones igualitarias.

La exclusión enfatiza un estado general de desigualdad de género. Las labores del hogar, de acuerdo con la estadística del Instituto Nacional de Estadística y Geografía (INEGI), son realizadas mayormente por mujeres, en razón de nueve de cada diez empleados en el país.

Los efectos de esta decisión, de alcances estructurales, consistieron en ordenar al Instituto Mexicano del Seguro Social (IMSS) que, durante el primer semestre de 2019, implemente un programa "piloto» que diseñe un régimen especial de seguridad social para estas trabajadoras. Además, deben preverse facilidades administrativas que permitan a los patrones cumplir con sus obligaciones, sin que deban necesariamente inscribirse en el servicio de administración tributaria, considerando que la gran mayoría de empleadores son amas de casa o padres de familia.

Finalmente, la sentencia estableció que en un plazo no mayor a dieciocho meses, a partir de la implementación del programa piloto, el IMSS proponga al Congreso de la Unión las adecuaciones legales necesarias para la incorporación formal del nuevo sistema de seguridad social para las trabajadoras del hogar. De manera tal que, en un plazo no mayor a tres años, se consigan las condiciones jurídicas de seguridad de manera «efectiva, robusta y suficiente a la totalidad de las empleadas domésticas del país» 5 .

5 Ponente: Alberto Pérez Dayán. Unanimidad de cinco votos. Sesión del 5 de diciembre de 2018. De este asunto, se desprendieron las tesis aisladas: 2a. XXX/2019, 2a. XXXI/2019 y 2a. XXXII/2019, SJF, de 17 de mayo de 2019. 


\section{IDENTIDAD DE GÉNERO AUTOPERCIBIDA (REASIGNACIÓN SEXO-GENÉRICA)}

En el estado de Veracruz, una persona solicitó la reasignación sexo-genérica, consistente en la adecuación de su nombre y el dato alusivo a su género. El titular del registro civil municipal se negó a darle trámite a la modificación. El fundamento de su negativa fue el art. 759 del Código Civil de ese estado, que disponía que ese tipo de procedimientos debía sustanciarse ante el Poder Judicial, el cual debía publicitar la solicitud y permitir la intervención de terceros. La persona solicitante promovió entonces un juicio de amparo en contra de esa disposición y de la propia negativa.

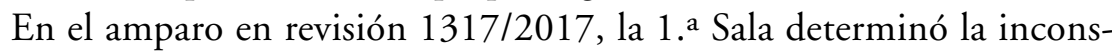
titucionalidad del precepto. La medida legislativa resultó discriminatoria porque no permitía la adecuación de la identidad de género mediante un procedimiento administrativo, cuando este sí estaba previsto para otras modificaciones esenciales del registro civil. El cambio de nombre y la adecuación de registros públicos y de documentos de identidad conforme al género autopercibido constituye un derecho protegido tanto a la luz de la Convención Americana sobre Derechos Humanos como por la Constitución mexicana. Sus fundamentos son de amplio rango, pues está involucrada la protección del derecho al libre desarrollo de la personalidad, el derecho a la privacidad, el reconocimiento de la personalidad jurídica y el derecho al nombre.

La Corte concluyó que el procedimiento idóneo para la reasignación sexo-genérica debe ser formal y materialmente administrativo. Para el cumplimiento de su propósito, deben cumplirse los siguientes cinco requisitos: a) debe estar enfocado a la adecuación integral de la identidad de género autopercibida; b) debe basarse únicamente en el consentimiento libre e informado del solicitante, sin que puedan exigirse otros requisitos tales como certificaciones médicas y/o psicológicas, u otros que puedan resultar irrazonables o patologizantes; c) debe ser confidencial, además de que los cambios, correcciones o adecuaciones en los registros y documentos de identidad no deben reflejar los cambios solicitados en la identidad de género, aunque sí deben tomarse medidas que permitan evitar defraudar a terceros con motivo de ello; d) debe ser expedito y, en la medida de lo posible, tender a la gratuidad, y e) no debe exigir la acreditación de operaciones quirúrgicas y/u hormonales. 
En consecuencia, se ordenó al encargado del registro civil dar trámite administrativo a la solicitud de mérito y a dejar de aplicar las normas del procedimiento que no resultaran compatibles con esos requisitos ${ }^{6}$.

\section{REPRODUCCIÓN ASISTIDA DE LAS PAREJAS DEL MISMO SEXO Y FILIACIÓN DE SUS HIJOS}

Un matrimonio homosexual de varones consiguió la procreación de un hijo con nexo biológico mediante el procedimiento de maternidad subrogada al que se sometió una mujer. La fecundación se produjo a partir de esperma proveniente de uno de ellos, mientras que el óvulo provino de la donante anónima.

La pareja solicitó ante una oficina de registro civil del estado de Yucatán la inscripción del menor con los apellidos de ambos integrantes del matrimonio. La autoridad negó la inscripción bajo el argumento de que la legislación de la materia no preveía ese supuesto, sin reconocerles, por tanto, el derecho al nombre en vía de parentesco por consanguinidad.

En el amparo en revisión 553/2018, la 1. a Sala consideró que el análisis de los requisitos, condiciones o procedimientos que deban seguirse para llevar a cabo la maternidad subrogada, en el que se garantice la protección de los derechos del niño y de la madre gestante, así como de quienes acceden a esa técnica para convertirse en padres, excedía la materia del juicio.

Sin embargo, ante la realidad fáctica de que se estaba ante un niño nacido mediante una maternidad subrogada, la Corte consideró que sí debía analizarse la manera de establecer la filiación jurídica del menor. Razonó que sí era factible establecer la filiación con un hijo nacido por una técnica de reproducción asistida a través de los mecanismos de reconocimiento o presunción de paternidad o maternidad previstos en la ley.

En estas condiciones, es central acreditar la voluntad en la procreación expresada por la pareja del mismo sexo. Pero también el consentimiento de la madre gestante en cuanto a su voluntad de no reclamar derechos y la consecuente aceptación de que sean el progenitor biológico y su pareja quienes mantengan la condición de padres del niño y, por tanto, asuman todas las obligaciones derivadas de la filiación.

6 Ponente: Norma Lucía Piña Hernández. Mayoría de cuatro votos. Sesión del 17 de octubre de 2018. A partir de este caso, se emitieron cinco tesis: de la 1a. CCXXXI/2018 a la 1a. CCXXXV/2018, SJF, de 7 de diciembre de 2018. 
En el caso, se acreditó la voluntad de la madre, al tratarse de una mujer mayor de edad, con capacidad legal para ello, que se expresó sin vicios invalidantes, y sin existir indicios en contrario. Así, en virtud del principio del interés superior de la niñez, se estableció la filiación del menor respecto de la pareja. Se le reconocieron todos los derechos prestacionales derivados de la filiación: alimentos, los sucesorios, a recibir cuidados, educación y afecto. Condiciones que, por lo demás — quedó demostrado en el caso-, le habían sido provistas por la pareja que se hizo cargo de él desde su nacimiento.

En consecuencia, se concedió el amparo para el efecto de que el menor fuera registrado como hijo del matrimonio, garantizándosele el derecho a contar con una identidad y a ser inscrito en el registro civil. Se reconoció el derecho de los padres a su vida privada y a procrear mediante el acceso a los adelantos de la ciencia a través de técnicas de reproducción asistida, sin distinción de preferencia sexual. Finalmente, también fue reconocido el derecho de la madre subrogada a la propia vida privada y al libre desarrollo de su personalidad ${ }^{7}$.

\section{EDUCACIÓN INCLUSIVA DE LOS NIÑOS Y NIÑAS CON DISCAPACIDAD}

La 2. ${ }^{a}$ Sala emitió diversos criterios en torno al derecho a la educación inclusiva de los niños y niñas con discapacidad. Destacan dos casos. En el amparo en revisión 714/2017 analizó la constitucionalidad de varios preceptos de la Ley General de Educación y la Ley General para la Atención y Protección a Personas con la Condición del Espectro Autista, que introdujeron un régimen de «educación especial».

La Corte sostuvo que en el Estado mexicano no puede concebirse la existencia de dos sistemas educativos: uno regular u ordinario para todo el alumnado y otro presuntamente «especial» para alumnos con discapacidad. Todos los niños y niñas tienen el derecho fundamental a la educación inclusiva y deben integrarse en un solo sistema educativo general, sin reglas, ni excepciones pretendidamente legítimas. Cualquier exclusión basada en alguna discapacidad, por tanto, debe calificarse como discriminatoria.

El sistema educativo general debe complementarse con herramientas de apoyo para conseguir la inclusión. Con base en ellas, deben identificarse,

7 Ponente: José Ramón Cossío Díaz. Unanimidad de cinco votos. Sesión del 21 de noviembre de 2018. De este amparo surgieron las tesis: 1a. LXXXVII/2019 y 1 a. LXXXVIII/2019, SJF, de 11 de octubre de 2019. 
prevenirse y eliminarse las barreras que limiten el aprendizaje y la participación plena y efectiva de niños con discapacidad. Las políticas y recursos encaminados a lógicas inclusivas deben primar sobre prácticas que tiendan a la separación, temporal o definitiva, de los niños. Esas políticas deben atender al principio de progresividad y, hasta el máximo de los recursos disponibles, adoptar ajustes razonables, como pueden ser: la capacitación de profesores, adaptaciones de aulas de clase a las diversas necesidades del alumnado, o elaboración y revisión de planes de estudio que tome en cuenta esa diversidad.

La educación inclusiva tiene como propósito que todos los niños cuenten con oportunidades de convertirse en miembros productivos de la sociedad y de formar parte de su comunidad. En consecuencia, se declaró la inconstitucionalidad del precepto que establecía la coexistencia de dos sistemas educativos diferenciados ${ }^{8}$.

En similar tónica, más adelante, en el amparo directo 31/2018, la propia

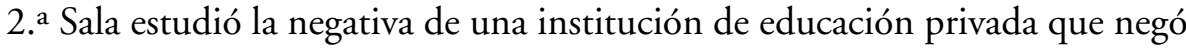
la reinscripción al $2 .^{\circ}$ grado de educación secundaria a un alumno diagnosticado con trastorno por déficit de atención con hiperactividad (TDAH). Las razones aportadas por la institución fueron la supuesta indisciplina del menor y que dicha institución no era una escuela adecuada para recibirlo, dada la discapacidad del menor, que, en su opinión, ameritaba su asistencia a una escuela especial.

La Corte desestimó esa argumentación y concedió el amparo. Si la restricción o negación en el acceso a la educación atiende al actuar "atípico», «irregular» o «especial» de un alumno, a sabiendas de que cuenta con una discapacidad, surge la presunción de que esa decisión constituye un acto discriminatorio. La carga de la prueba de que ello no es así recae en la autoridad o institución, pública o privada, que ha afectado el derecho fundamental a la educación inclusiva. Esto significa que la institución debe acreditar que esa afectación no deriva de la discapacidad del alumno, sino de factores ajenos a ello.

En el caso, se consideró que la institución educativa no consiguió demostrar que la indisciplina del alumno rechazado atendía a cuestiones ajenas al trastorno que padecía. Por tanto, se concluyó que el rechazo de la reinscripción del menor de edad se basó exclusivamente en su discapacidad.

El derecho a la educación inclusiva y a la igualdad implica que los sistemas educativos dejen de considerar «diferentes» a alumnos con discapacidad,

8 Ponente: Alberto Pérez Dayán. Unanimidad de cuatro votos. Sesión del 3 de octubre de 2018. Las tesis que emanaron de este asunto fueron seis: de la 2a. III/2019 a la $2 \mathrm{a}$. VIII/2019, SJF, de 8 de febrero de 2019. 
viabilizar la diversidad del alumnado, y atender sus necesidades individuales para enriquecer los métodos de enseñanza. De esta manera, debe considerarse prohibida la exclusión de personas con discapacidad en instituciones educativas públicas y privadas, las cuales están obligadas a implementar ajustes razonables. Ello significa la implementación de medidas personalizadas de apoyo que busquen identificar y eliminar barreras y obstáculos de aprendizaje que padezcan los niños en situación de discapacidad?.

\section{VIDA Y SALUD DE LOS NIÑOS FRENTE A CREENCIAS RELIGIOSAS DE SUS PADRES}

Como ha ocurrido en otros altos tribunales, la Corte mexicana resolvió un caso en el que el derecho a la vida y la salud de una menor de edad se enfrentó con el derecho de sus padres a materializar sus convicciones religiosas. En los hechos analizados en el amparo en revisión 1049/2017, una niña de 6 años con leucemia linfoblástica aguda había ingresado en un hospital en condición de urgencia. Los médicos prescribieron que requería transfusiones sanguíneas. Pero sus padres se opusieron con base en sus creencias religiosas.

La Subprocuraduría de Menores, tras escuchar a los padres y a los médicos, ante lo delicado de la situación, decidió asumir la tutela de la niña y autorizar el tratamiento médico indicado. La madre de la menor reclamó que la Subprocuraduría reemplazó de forma injustificada su derecho a decidir libremente sobre la salud de su hija.

La Corte determinó que, si bien los padres tienen derecho a tomar decisiones sobre sus hijos, tanto en el ámbito de la salud como en el de la educación religiosa, ese derecho tiene como límite poner en riesgo la propia salud y la vida de los hijos.

Ese límite se actualiza cuando los padres rehúsan seguir un tratamiento que ha sido determinado por la comunidad científica como el procedimiento más efectivo para tratar una condición letal. Si ese procedimiento no suscita una disputa científica sustancial sobre su confianza y confiabilidad, se erige en una restricción legítima al ejercicio de su derecho a decidir.

En el caso, la Corte resolvió que debía sustituirse la voluntad de los padres. El tratamiento indicado por los profesionales médicos se encontraba basado en suficiente evidencia científica, consistente en la realización necesa-

9 Ponente: Alberto Pérez Dayán. Mayoría de cuatro votos. Sesión del 14 de noviembre de 2018. No hay constancia de que en este asunto se hayan generado tesis jurisprudenciales. 
ria de quimioterapias simultáneas con transfusiones sanguíneas a la niña. Era la única intervención que podía proteger su vida. Finalmente, se estableció la necesidad de la estricta supervisión de los procedimientos por parte de las autoridades y que la sustitución de la voluntad paternal debía considerar un trato digno, incluyente y respetuoso hacia los padres ${ }^{10}$.

\section{PROTECCIÓN DEL BIENESTAR ANIMAL FRENTE A EXPRESIONES CULTURALES: LA PROHIBICIÓN DE PELEAS DE GALLOS}

La Ley de Protección a los Animales para el estado de Veracruz prohibió las peleas de gallos. En México, esa actividad lúdica con esta clase de aves generalmente se realiza en contextos de fiestas populares. Unas personas promovieron juicio de amparo por considerar que dicha prohibición vulneraba su derecho a la cultura, la propiedad y la libertad de trabajo, así como el derecho a la igualdad y la no discriminación.

En el amparo en revisión 163/2018, la 1. a Sala determinó la constitucionalidad de la prohibición y negó el amparo. Estableció que, si bien las peleas de gallos pueden constituir la manifestación de una determinada cultura, ninguna práctica que implique el maltrato o sufrimiento innecesario de los animales puede considerarse como una expresión cultural amparada por la Constitución.

Se reconoció que la prohibición sí afecta el derecho a la propiedad sobre las aves y la libertad de trabajo de las personas que se dedican a organizar esta clase de "peleas». La Corte aclara que esta afectación no resulta desproporcionada en atención a la finalidad legítima que persiguen estas normas y que justifica legítimamente la restricción de esos derechos fundamentales: la protección del bienestar animal.

La prohibición de peleas de gallos es una medida idónea y necesaria para garantizar la protección del bienestar animal. Además, a partir del test de proporcionalidad, puede también concluirse que el grado en que se consigue esa protección compensa las afectaciones a los derechos de propiedad sobre las aves y la libertad de trabajo de las personas.

En relación con la supuesta vulneración del derecho a la igualdad y la no discriminación se determinó que excluir las peleas de gallos de las actividades a las que no aplica la ley, cuando el legislador trata de modo distinto las

10 Ponente: Arturo Zaldívar Lelo de Larrea. Mayoría de cuatro votos. Sesión del 15 de agosto de 2018. En este caso, se produjeron doce tesis jurisprudenciales: desde la 1a. II/2019 a la 1a. XIII/2019, SJF, de 8 de febrero de 2019. 
corridas de toros, tampoco justifica la legitimidad de la medida. La pregunta formulada por quienes promovieron el amparo tenía sentido en la medida en que ambas actividades supondrían un maltrato a los animales.

La Corte resolvió en el sentido de que no podría considerarse la inclusión de peleas de gallos como actividad permitida con el argumento de que es sustancialmente equivalente a las corridas de toros, que el legislador excluye de la prohibición. El hecho de que las corridas de toros no se prohíban expresamente no justifica que deban permitirse implícitamente todas las actividades que impliquen un maltrato a los animales. El derecho a la igualdad no significa que los demandantes del amparo puedan beneficiarse de una incongruencia del legislador al prohibir de modo explícito una actividad y no la otra ${ }^{11}$.

\section{PRECISIÓN AL FUERO JURISDICCIONAL DEL ORDEN MILITAR}

Desde la recepción por la Suprema Corte de la sentencia condenatoria de la Corte Interamericana al Estado mexicano en el caso Radilla Pacheco ${ }^{12}$, hubo que implementar la prohibición del fuero militar cuando en los hechos de los casos judiciales, además de involucrar a personas pertenecientes al Ejército, estuvieran implicadas personas civiles.

En los hechos del amparo en revisión 605/2014, la persona sujeta al proceso penal era comandante de una base de operaciones que tenía por actividad específica el combate al narcotráfico. Había sido acusado de delitos contra salud y traición a las fuerzas armadas.

El tribunal pleno de la Corte determinó que cuando un militar, en sus actos de servicio, comete delitos que atentan de manera directa contra la disciplina castrense, ese caso debe ser resuelto por un juez militar y no uno civil, siempre que en los hechos no esté involucrado un civil (ya sea como sujeto activo o en condición de víctima), ni se trate de violaciones a derechos humanos.

Ahora bien, la Corte estableció que, para que se actualice el fuero militar, no basta con que el imputado sea un militar en activo y no esté involucrado un civil. Es necesario que el delito se cometa en actos del servicio y que guarde estricta conexión con la disciplina castrense, como bien jurídico tutelado.

Así, en el caso, se revocó la sentencia de amparo a favor del comandante: en su circunstancia correspondía al juez militar conocer de la causa, pues la

11 Ponente: Arturo Zaldívar Lelo de Larrea. Unanimidad de cinco votos. Sesión del 31 de octubre de 2018. No hay constancia de que en este caso se hayan producido tesis jurisprudenciales.

12 Ese trascendente caso fue reseñado en Herrera García (2012). 
sentencia revocada en este asunto había sido considerada inadecuadamente como competencia de un juez civil ${ }^{13}$.

\section{MODALIDADES LEGALES DEL DERECHO DE RÉPLICA}

Mediante una acción abstracta de inconstitucionalidad en contra de la Ley del Derecho de Réplica, la Corte consideró que este derecho no debe concebirse como un límite a la libertad de expresión, sino como un derecho que la complementa ${ }^{14}$. La réplica trata de posibilitar el acceso a la información disponible cuando el interesado estima que la originalmente compartida contiene falsedades o manipulaciones.

Entre los diversos conceptos de invalidez analizados en este caso, merece la pena destacar dos.

El primero implicó el análisis de la obligación de acompañar, en el procedimiento judicial de réplica, las pruebas que demuestren la falsedad o inexactitud de la información, "o el perjuicio que dicha información hubiera ocasionado".

La Corte determinó la invalidez de exigir pruebas que pretendan acreditar el "perjuicio». Acreditar un perjuicio equivale a exigir una prueba de agravio, cuando para ejercer una réplica el agravio se prueba con el simple hecho de aludir que se trata de información falsa o inexacta. Por tanto, ese requisito constituye una carga adicional innecesaria y repetitiva para el ejercicio del derecho. Por otro lado, ese requisito tampoco se podría entender como optativo. Pues si optara el interesado por presentar la prueba de perjuicio, y no la de falsedad o inexactitud, podría comprenderse que la réplica procede frente a información cierta, cuando el propósito del derecho no es combatir cualquier información (menos la verdadera), sino la falsa o inexacta ${ }^{15}$.

El segundo aspecto de interés en este caso fue el plazo establecido por el legislador para promover la réplica: «[...] un plazo no mayor a cinco días hábiles, contados a partir del siguiente al de la publicación o transmisión de la información que se desea rectificar o responder». La Corte consideró que ese plazo resulta inconstitucional. Si bien el legislador es libre de elegir los plazos

13 Ponente: Alfredo Gutiérrez Ortiz Mena. Mayoría de siete votos. Sesión del 26 de febrero de 2018.

14 Acción de inconstitucionalidad 122/2015 y sus acumuladas 124/2015 y 125/2015. Ponente: Javier Laynez Potisek. Sesión del 1 de febrero de 2018. Sentencia publicada en el Diario Oficial de la Federación el 24 de abril de 2018.

15 Este tema recibió una votación de ocho votos por la invalidez en el tribunal pleno. 
que estime por conveniente, en este caso debió guardar un balance entre el derecho a la seguridad jurídica de los medios de comunicación, que pueden convertirse en sujetos obligados, y el derecho a la oportunidad de los sujetos afectados para ejercer su derecho de réplica. La medida legislativa no consigue un balance real, sino que pone en riesgo el ejercicio efectivo del derecho. La Corte indicó que esta invalidez debía surtir sus efectos a partir de los noventa días naturales siguientes al día de la publicación de la sentencia en el Diario Oficial. Dentro de ese plazo el Congreso de la Unión debía definir y sustituir el advertido vicio de temporalidad ${ }^{16}$.

\section{INSPECCIONES POLICIALES Y GEOLOCALIZACIÓN EN EL CÓDIGO NACIONAL DE PROCEDIMIENTOS PENALES}

Este Código, nuclear para el funcionamiento del sistema procesal penal mexicano, fue publicado el 5 de marzo de 2014 en el Diario Oficial de la Federación. Varias de sus disposiciones fueron impugnadas en vía de control abstracto $^{17}$. De entre las múltiples cuestiones debatidas por la Corte, me referiré solamente a dos: las que incidieron en la tutela de la libertad personal en contextos de sospechas policiales y las relativas a la geolocalización de teléfonos móviles.

En su art. 268, el Código previó lo siguiente: i) que la policía tiene por obligaciones practicar inspecciones y reportar sus resultados al ministerio público; ii) en casos en que se requiera autorización judicial, deberá obtenerla a través del ministerio público; iii) dentro de las actuaciones en la investigación que no requieren autorización previa del juez de control, puede haber inspección de personas y vehículos; iv) que en la investigación de los delitos la policía puede realizar la inspección sobre una persona y sus posesiones en caso de flagrancia; o en caso de que haya indicios de que oculta entre sus ropas o que lleva adheridos a su cuerpo instrumentos, objetos o productos relacionados con el hecho delictivo; v) la revisión consistirá en una exploración externa de la persona y sus posesiones; vi) en el caso de la detención en flagrancia, la inspección realizada por los cuerpos de seguridad pública deberá conducirse conforme a los lineamientos establecidos en el propio Código, y vii) solo si la

16 Este punto tuvo una votación de nueve votos por la invalidez en el tribunal pleno.

17 Se trata de la acción de inconstitucionalidad 10/2014 y su acumulada 11/2014. Ponente: Javier Laynez Potisek. Sesión del 22 de marzo de 2018. Sentencia publicada en el Diario Oficial de la Federación el 25 de junio de 2018. 
persona no está dispuesta a cooperar, o se resiste, se podrá realizar un registro forzoso.

El conjunto de estos supuestos fue impugnado. La Corte señaló que deben distinguirse al menos dos grandes supuestos en materia de inspecciones policiales: a) la flagrancia, y b) la que tiene lugar durante la investigación de delitos.

Respecto a las inspecciones en flagrancia, debe considerarse el grado de intensidad de la conducta de la que deriva la sospecha razonable para determinar el control preventivo, a la luz de dos grados:

a) Un control preventivo de grado menor, que implica que los agentes de la policía pueden limitar provisionalmente el tránsito de personas y/o vehículos con la finalidad de solicitar información a la persona controlada, como, por ejemplo, su identidad, ruta, motivos de su presencia, etcétera. En esa tónica, la policía estaría en posibilidad de realizar una revisión ocular superficial exterior de la persona o del interior de algún vehículo.

b) Un control preventivo de grado superior, que está motivado objetivamente por conductas proporcionales y razonablemente sospechosas. Implica que los agentes policiales están en la posibilidad de realizar sobre la persona y/o vehículos un registro más profundo, con la finalidad de prevenir algún delito, así como para salvaguardar la integridad y la vida de los propios agentes. En estas condiciones, dichos agentes podrían, además, registrar las ropas de las personas, sus pertenencias, así como el interior de los vehículos. Esto ocurriría, por ejemplo, si las circunstancias objetivas y particulares que rodean a un delito y al sujeto activo corresponden ampliamente con las descritas en una denuncia previa, o si los sujetos controlados muestran un alto nivel de desafío o de evasión frente a los agentes de autoridad.

En este sentido, si, tras un control provisional preventivo legítimo, los agentes de la policía advierten la comisión flagrante de algún delito, la detención del sujeto controlado será lícita y, en consecuencia, también lo serán las pruebas descubiertas en la revisión, que, a su vez, tendrán valor jurídico pleno para su ofrecimiento en juicio.

En relación con inspecciones durante la investigación de delitos, se estableció que la sospecha razonable comienza a construirse a partir de los datos e informaciones derivados de una denuncia previa. Ello puede verificarse, por ejemplo, a partir de la descripción física o apariencia del sujeto aportados en la denuncia, información obtenida sobre su ubicación o posible zona o lugar de localización, la descripción de un vehículo en el que conducía o se encontraba en el momento de los hechos, entre otros supuestos. Todo ello puede 
justificar, en un primer momento, una aproximación y primer contacto con el sujeto sospechoso.

Sin embargo, estos datos e informaciones, por sí solos, no dan lugar a la práctica inmediata o automática de la inspección. En este punto, la sospecha razonable aún no se materializa. Previo a ello, es necesario que el agente de seguridad se aproxime al sujeto, se identifique como tal y solicite que él haga lo propio. Posteriormente, emprenderá una entrevista, explicando las razones por las que se realiza y, a partir de las respuestas obtenidas y/o de la actitud $\mathrm{y}$ acciones que al efecto asuma la persona, junto con la información con que se contaba, y demás circunstancias del caso, ya podría actualizarse una verdadera sospecha razonable, requisito indispensable para la inspección física de la persona ${ }^{18}$.

Otro punto a destacar, a partir del análisis de este Código Nacional, es el estudio de constitucionalidad de la geolocalización de teléfonos móviles prevista en su art. 303. Este precepto autorizaba al ministerio público a solicitar la ubicación geográfica de equipos de comunicación móvil asociados a una línea telefónica, supuestamente involucrada en la investigación de hechos delictivos. A partir del mismo precepto, para las compañías telefónicas se actualizaba la obligación de entregar esa ubicación.

La Corte aplicó un test de proporcionalidad, del que se desprendieron las siguientes conclusiones:

a) La geolocalización persigue un fin constitucionalmente legítimo: la prevención, investigación y persecución de delitos, que, a su vez, tiene como objetivo preservar la vida, integridad personal, patrimonio y seguridad de la población.

b) La geolocalización es una medida idónea para cumplir con el fin perseguido en tanto que constituye una herramienta que facilita y dota de eficacia a la función constitucional de prevención, investigación y persecución del delito. Mediante la utilización de esta tecnología, se puede ubicar geográficamente a personas asociadas a delitos y, con ello, aumentar la probabilidad de que estos sean capturados y procesados.

c) Respecto a la necesidad de la medida se argumentó la existencia de altos índices de delincuencia en el país, lo cual hace necesario el uso de estas tecnologías bajo la consideración de que pueden llevar a mejores y más eficientes resultados que las técnicas tradicionales de persecución de los delitos.

18 El art. 268 del Código, que involucró estas consideraciones jurídicas, recibió siete votos a favor de su validez en el tribunal pleno. 
d) Sin embargo, finalmente, se consideró que la geolocalización no cumple con la proporcionalidad en sentido estricto. El art. 303 no establece los supuestos o casos excepcionales en los que la geolocalización puede utilizarse por el ministerio público. La medida restringe el derecho a la intimidad en el caso de delitos menores o que no ponen en alto riesgo la vida, integridad y seguridad de una persona, y, por tanto, no cumple con la proporcionalidad en sentido estricto porque la afectación al derecho es mucho mayor a la importancia del fin perseguido. Por tanto, en esos casos, no se justificaría una invasión a la privacidad, ni siquiera para efectos de la prevención, investigación y persecución de esos delitos.

Para que la medida superara el test de proporcionalidad debía estar restringida solo a los delitos más gravosos para la población o en los supuestos de urgencia, es decir: i) cuando se pongan en riesgo la vida o integridad física de las víctimas del delito, o ii) cuando exista riesgo de que se oculte o desaparezca el objeto del delito, en los que la geolocalización, por sus características y la información que provee, juega un papel central o fundamental en la investigación del ilícito ${ }^{19}$.

\section{CONSTITUCIÓN DE LA CIUDAD DE MÉXICO: ¿̇FEDERALISMO DE LOS DERECHOS HUMANOS?}

El debate que suscitó la acción de inconstitucionalidad en contra de la Constitución de la Ciudad de México - la primera en la historia para la capital del país- fue el más prolongado del año en el tribunal pleno ${ }^{20}$. Este ordenamiento fue producto de un complejo proceso constituyente que culminó con la aprobación de la Constitución capitalina el 31 de enero de 2017. Esta Constitución acogió una generosa carta de derechos y novedosas bases político-administrativas para la Ciudad, con fundamento en el art. 122 de la

19 En el tribunal pleno se verificaron ocho votos por la invalidez del precepto impugnado. Esta temática ya había sido tratada por la Corte en otra ocasión, cuando analizó la constitucionalidad de la geolocalización en el abrogado Código Federal de Procedimientos Penales, con diverso resultado (acción de inconstitucionalidad 32/2012). Me referí a ese caso en Herrera García, 2014. Véase, asimismo, la postura en este asunto de Cossío Díaz (2019).

20 La acción de inconstitucionalidad 15/2017 y sus acumuladas 16/2017, 18/2017 y 19/2017 se discutió a lo largo de 9 sesiones plenarias. Ponente: Javier Laynez Potisek. Sesión de resolución: 6 de septiembre de 2018. Sentencia publicada en el Diario Oficial de la Federación el 25 de abril de 2019. 
Constitución Federal. En la actualidad, la Ciudad se equipara institucionalmente al resto de los 31 estados que integran la Federación. Pero esas novedades plantearon un amplio conjunto de interrogantes en torno a su validez.

Una de las múltiples impugnaciones que se formularon fue la posibilidad para la Ciudad de México de desarrollar, y hasta qué punto, normas de derechos humanos. La inquietud derivó de que varios de los derechos establecidos en la nueva Constitución tenían un alcance protectivo mayor, o distinto, a los previstos en la Constitución Federal o en tratados internacionales.

La Corte determinó que las autoridades legislativas locales tienen facultades para reconocer, ampliar o desarrollar normas de derechos humanos, o incluso crear derechos nuevos, pues ello no necesariamente significa alterar o modificar el parámetro de regularidad constitucional federal. No se trata de una atribución exclusiva del Congreso de la Unión: las entidades federativas pueden, en principio, válidamente establecer normas de derechos en sus constituciones. Esta atribución tiene sus límites en la no alteración de la identidad o el contenido esencial de normas federales o internacionales en la materia ${ }^{21}$.

Enseguida, la Corte analizó contenidos normativos concretos de diversos derechos. Destacaré únicamente dos. Avaló la constitucionalidad del polémico derecho al «uso médico y terapéutico de la cannabis sativa, de conformidad con la Constitución [Federal] y la legislación aplicable». Determinó que esta norma no conlleva una función prescriptiva sobre la forma y términos en los que deben prestarse los servicios de salubridad general en materia de estupefacientes, ni, en específico, sobre la cannabis. Precisó que tampoco implicaba una ampliación o reconocimiento de derechos que interfiriera con atribuciones de otro nivel de gobierno. En ese sentido, concluyó que no se afectó la competencia de la Federación, que es la facultada para regular todas las actividades relacionadas con estupefacientes.

También se controvirtió la norma que estableció: «La vida digna contiene implícitamente el derecho a una muerte digna». Para la Procuraduría actora este precepto reconocía implícitamente la eutanasia y el suicidio asistido sin que existiera competencia local en materia de salud para regularlos. La Corte validó el precepto bajo el argumento de que no es posible advertir una inconstitucionalidad en abstracto. A su juicio, será hasta conocer el contenido normativo de los instrumentos legales que la Ciudad de México considere útiles para garantizar el derecho a una muerte digna cuando pueda verificarse si se viola, o no, alguna competencia exclusiva de la Federación en este tema ${ }^{22}$.

21 Esta decisión por la validez alcanzó la unanimidad de once votos en el tribunal pleno.

22 El criterio por la validez respecto de sendos derechos fue sostenido por nueve votos en el tribunal pleno. 
Por otro lado, se analizó la posibilidad de desarrollo normativo de algunos elementos del procedimiento de control de actos de autoridad frente a la Constitución federal. En este aspecto, la Corte determinó que a las autoridades legislativas locales no les es disponible el concepto de "parámetro de regularidad» de los derechos humanos. Incluir en esa figura a la Constitución federal y los tratados calificándolos como "parámetro local» "genera incertidumbre» en el control que realicen los tribunales locales. A su juicio, tampoco es válido que las normas locales dispongan que los jueces puedan inaplicar normas bajo parámetros federales o internacionales por al menos dos razones: la incompetencia local para regular el parámetro y porque, lejos de tender a la uniformidad de criterios, "podría generar un esquema diferenciado y múltiple» de control en las entidades federativas ${ }^{23}$.

\section{INCONSTITUCIONALIDAD DE LA LEY DE SEGURIDAD INTERIOR}

Bajo el sexenio del presidente Enrique Peña Nieto (2012-2018), el Congreso de la Unión publicó la Ley de Seguridad Interior en el Diario Oficial de la Federación el 21 de diciembre de 2017. Poco antes de cumplirse un año desde su promulgación, la Corte invalidó la totalidad de esta ley al resolver una acción de inconstitucionalidad ${ }^{24}$.

La Corte consideró que la ley era inconstitucional por haberse emitido por el Congreso Federal, órgano que, a su juicio, resulta incompetente para legislar en materia de «seguridad interior». Dijo que el Poder Legislativo solamente puede legislar sobre materias que le fueron expresamente concedidas por la Constitución. Una expansión injustificada de competencias federales ampliaría de manera velada el orden legislativo federal.

La ley distinguía entre las funciones de «seguridad interior» y de «seguridad pública», aunque constitucionalmente no exista diferencia material entre ellas. Cada tipo de «seguridad» se hace depender exclusivamente de la autoridad que la tiene legalmente encomendada. La seguridad interior, en cuanto vertiente de la seguridad nacional, se pretende atribuida ilegítimamente a las

23 La votación en el pleno respecto de estos puntos fue por mayoría de diez y nueve, respectivamente. Una breve exposición de mi opinión, contraria a estos argumentos, puede verse en Herrera García, 2019.

24 Acción de inconstitucionalidad 6/2018 y sus acumuladas 8/2018, 9/2018, 10/2018 y 11/2018. Ponente: Jorge Mario Pardo Rebolledo. Encargado del engrose: Eduardo Medina Mora. Sesión del 15 de noviembre de 2018. Sentencia publicada en el Diario Oficial de la Federación el 30 de mayo de 2019. 
fuerzas armadas; mientras que la seguridad pública se atribuye a las autoridades civiles.

La sentencia argumenta que esa distinción constituye un fraude a la Constitución: permite la participación regular de las fuerzas armadas en la función de garantía de la seguridad pública, la cual solamente puede ser realizada por las autoridades civiles en términos del art. 21 de la Constitución y de la Convención Americana sobre Derechos Humanos. La ley pretendía encubrir la participación de las fuerzas armadas en funciones de seguridad pública. Una ley no puede ser fundamento de una competencia constitucional que incluya contenidos materiales de otra competencia, con alcances, parámetros y objetos diferentes.

Cabe mencionar que la seguridad pública se mantiene en el centro de una profunda problemática social, y también jurídica, en México. El 28 de noviembre de 2018 (trece días después de haberse dictado la sentencia), la Corte Interamericana de Derechos Humanos notificó una nueva condena al Estado mexicano en el caso Alvarado Espinoza y otros. En ese caso, entre otras cosas, reiteró y estableció para México estándares relacionados con la participación de las fuerzas armadas en tareas de seguridad pública y sus condiciones de excepción ${ }^{25}$.

Además, ya en el sexenio presidencial actual, con Andrés Manuel López Obrador al frente, la Constitución mexicana fue reformada para establecer las bases normativas de la denominada «Guardia Nacional», con el propósito de que esta novedosa organización asuma el combate a la aguda inseguridad pública que padece el país ${ }^{26}$. Pese a su configuración constitucional como institución policial de carácter civil, el art. 5..$^{\circ}$ transitorio del decreto de esta reforma dejó establecido lo siguiente: «Durante los cinco años siguientes a la entrada en vigor del presente decreto, en tanto la Guardia Nacional desarrolla su estructura, capacidades e implantación territorial, el Presidente de la República podrá disponer de la fuerza armada permanente en tareas de seguridad pública de manera extraordinaria, regulada, fiscalizada, subordinada y complementaria».

Como puede verse, nos encontramos ante un tema controvertido, ubicado en la primera línea de importancia en los días que corren y para el futuro inmediato de la vida social y democrática de México.

25 La sentencia fue notificada al Estado mexicano el 20 de diciembre de 2018. Cfr. Corte IDH. Caso Alvarado Espinoza y otros vs. México. Fondo, Reparaciones y Costas. Sentencia de 28 de noviembre de 2018. Serie C n. 370.

26 Esta reforma de la Constitución fue publicada en el Diario Oficial de la Federación el 26 de marzo de 2019. 


\section{CONSIDERACIÓN CONCLUSIVA}

Los casos relevantes de la Suprema Corte mexicana a lo largo de 2018 demuestran una cierta consolidación de criterios en materias relacionadas con normas de derechos humanos. Esa línea de desarrollo en la jurisprudencia ha sido consistentemente ascendente desde que se verificó la reforma constitucional en esta materia el 10 de junio de 2011.

La aproximación hacia una década desde la entrada en vigor de esa reforma podría comprenderse como exitosa desde un punto de vista de la riqueza jurisprudencial generada por el máximo tribunal a partir de ella. Sin embargo, tras ese diagnóstico, dentro de los diversos retos en puerta, cabe destacar uno impostergable: la todavía inacabada traslación de criterios, aún básicos, hacia el trabajo jurisdiccional del resto de los tribunales, federales y locales, y, todavía más, su insuficiente interiorización en la conducta cotidiana de la mayoría de las autoridades.

En todo caso, se mantiene abierta la expectativa de que esas bases continúen un desarrollo progresivo y que la jurisprudencia de la Corte esté en cada vez mejores condiciones de incidir en la cultura jurídica. A largo plazo, un optimismo moderado nos indica que esa jurisprudencia puede contribuir a contrarrestar en algún sentido las problemáticas de desigualdad e inseguridad que estructuralmente persisten en el país.

\section{Bibliografía}

Cossío Díaz, J. R. (2019). Voto en contra. México: Debate.

Herrera García, A. (2012). Jurisprudencia constitucional de la Suprema Corte de Justicia de México en 2011. Anuario Iberoamericano de Justicia Constitucional, 16, 447-456. Disponible en: https://bit.ly/32hIyek.

- (2014). Geolocalización de teléfonos móviles y derecho a la privacidad. Nexos: El juego de la Suprema Corte [blog], 20-1-2014. Disponible en: https://bit. ly/2OACoRM.

- (2019). Sesión: Justicia constitucional local. La Barra. Revista de la Barra Mexicana-Colegio de Abogados, 109, 54-55. Disponible en: https://bit.ly/2OxQDH4.

Herrera García, A., Niembro Ortega, R. y Spigno, I. (2019). México. En R. Albert, D. Landau, P. Faraguna y S. Drugda (eds.). The I.CONnect-Clough Center 2018 Global Review of Constitutional Law (pp. 199-203). Chestnut Hill (Massachusetts): Clough Center for the Study of Constitutional Democracy. Disponible en: http://dx.doi.org/10.2139/ssrn. 3471638. 